\title{
Nanopore structure comparison between shale oil and shale gas: examples from the Bakken and Longmaxi Formations
}

\author{
Kouqi Liu ${ }^{1} \cdot$ Liang Wang $^{2} \cdot$ Mehdi Ostadhassan $^{1} \cdot$ Jie Zou $^{3} \cdot$ Bailey Bubach $^{1} \cdot$ Reza Rezaee $^{3}$
}

Received: 5 July 2018/ Published online: 26 November 2018

(C) The Author(s) 2018

\begin{abstract}
In order to analyze and compare the differences in pore structures between shale gas and shale oil formations, a few samples from the Longmaxi and Bakken Formations were collected and studied using X-ray diffraction, LECO TOC measurement, gas adsorption and field-emission scanning electron microscope. The results show that samples from the Bakken Formation have a higher TOC than those from the Longmaxi Formation. The Longmaxi Formation has higher micropore volume and larger micropore surface area and exhibited a smaller average distribution of microsize pores compared to the Bakken Formation. Both formations have similar meso-macropore volume. The Longmaxi Formation has a much larger meso-macropore surface area, which is corresponding to a smaller average meso-macropore size. $\mathrm{CO}_{2}$ adsorption data processing shows that the pore size of the majority of the micropores in the samples from the Longmaxi Formation is less than $1 \mathrm{~nm}$, while the pore size of the most of the micropores in the samples from the Bakken Formation is larger than $1 \mathrm{~nm}$. Both formations have the same number of pore clusters in the 2-20 nm range, but the Bakken Formation has two additional pore size groups with mean pore size diameters larger than $20 \mathrm{~nm}$. Multifractal analysis of pore size distribution curves that was derived from gas adsorption indicates that the samples from the Longmaxi Formation have more significant micropore heterogeneity and less meso-macropore heterogeneity. Abundant micropores as well as mesomacropores exist in the organic matter in the Longmaxi Formation, while the organic matter of the Bakken Formation hosts mainly micropores.
\end{abstract}

Keywords Shale gas $\cdot$ Shale oil $\cdot$ Pore structure $\cdot$ Gas adsorption · Pore family $\cdot$ Multifractal analysis

\section{Introduction}

Production from shale gas and shale oil reservoirs now makes a significant percentage of the total production of hydrocarbons. This has led to a dramatic increase in the number of

Edited by Yan-Hua Sun

Kouqi Liu

Kouqi.liu@ndus.edu

$\triangle$ Liang Wang

wangliang_swpu@163.com

1 Department of Petroleum Engineering, University of North Dakota, Grand Forks, ND 58202, USA

2 State Key Laboratory of Oil and Gas Reservoir Geology and Exploitation, Southwest Petroleum University, Chengdu 610500, China

3 Department of Petroleum Engineering, Curtin University, Perth 6151, Australia studies of these types of rocks from different angles, including pore structures (Mirzaei-Paiaman and Saboorian-Jooybari 2016; Zhao et al. 2019). It is well understood that pore structure can significantly influence storage capabilities and transport properties of these types of reservoirs (Cai and $\mathrm{Yu}$ 2011; Hu et al. 2017; Li et al. 2017a, b, c; Liu and Ostadhassan 2017; Mirzaei-Paiaman et al. 2015, 2018). This makes further investigation into pore structures and other relevant characteristics highly important.

The International Union of Pure and Applied Chemistry (IUPAC) has divided pores into three categories based on their size: micropores $(<2 \mathrm{~nm})$, mesopores $(2-50 \mathrm{~nm})$ and macropores ( $>50 \mathrm{~nm}$ ) (Rouquerolb et al. 1994). During the last decade, a wide range of methods has been applied to characterize these pores including: mercury intrusion porosimetry (MIP) (Gao and $\mathrm{Hu} 2013$ ), gas adsorption methods (Huang and Zhao 2017; Liu et al. 2017; Shao et al. 2017; Wang et al. 2016), small-angle neutron scattering (SANS) and ultra-small-angle neutron scattering (USANS) 
(Clarkson et al. 2013; Zhao et al. 2017a), nuclear magnetic resonance (Zhao et al. 2017b), direct observation methods such as field-emission scanning electron microscope (FESEM) (Klaver et al. 2012; Loucks et al. 2009; Liu and Ostadhassan 2017), atomic force microscopy (AFM) (Javadpour 2009; Liu et al. 2016), microfocus X-ray computed tomography ( $\mu-\mathrm{CT}$ ) (Li et al. 2017a, b, c; Su et al. 2018; Zhang et al. 2016) and transmission electron microscopy (TEM) (Bernard et al. 2012).

The majority of published studies that characterize pore structures of shale reservoirs have focused solely on shale gas or shale oil formations separately and do not present a comparative perspective (Bowker 2007; Wei et al. 2018; Yin et al. 2016; Zou et al. 2017). However, the comparison of pore structures between these two completely different types of reservoirs can help us to better understand pore structures and will result in more successful field operations.

The Longmaxi Formation, also known as "hot shale," is the leading shale gas target play in the Sichuan Basin, China (Yang et al. 2017). It is widely distributed and was deposited in a marine environment. It consists of black organic shale with an average total organic content (TOC) around $2.6 \%$, with siliceous shale, carbonaceous shale and argillaceous siltstone (Guo 2016). The Bakken Formation is one of the largest shale oil plays in the world spreading between USA and Canada and consists of three different members. The upper and lower members of the Bakken Formation have a high organic matter content (an average of $8 \%$ and $10 \%$ TOC, respectively), while the Middle Bakken is composed of mixed carbonates and fine-grained clastics. The upper and lower members are considered source rocks for the middle member which is the reservoir rock (Jin et al. 2015; Smith and Bustin 1995; Sonnonberg et al. 2011; Pitman et al. 2001).

In this study, we collected five samples from the Longmaxi Formation (Samples 1-5) and five samples from Bakken Formation (Upper Bakken) (Sample 6-10) to: (1) compare the pore volume and surface area of a wide range of pore sizes with $\mathrm{CO}_{2}$ and $\mathrm{N}_{2}$ adsorption methods, (2) quantify different numbers of pore families in the samples based on pore size distribution curves, (3) characterize pore structures and compare the heterogeneity of micropores and meso-macropores within the samples and finally, (4) present and compare the impact of rock composition on pore structures for each of these two formations separately.

\section{Materials and methods}

\subsection{Samples}

Five samples from the Longmaxi Formation in the Jiaoshiba Gas Field and 5 samples from the Bakken Formation in the Williston Basin in the State of North Dakota,
USA, were collected and prepared for the following set of analysis. Part of these samples have been analyzed in our previous study (Wang et al. 2016; Liu et al. 2017; 2018a b).

\subsection{Mineralogy and TOC}

Bulk mineralogical composition of the samples was analyzed using a Bruker D8 Advance X-ray diffractometer (XRD). The scanning measurements were performed at a rate of $2^{\circ} / \mathrm{min}$ in the $3^{\circ}-90^{\circ}$ range, and then the mineral compositions were estimated by analyzing the peaks (Liu et al. 2017). The TOC was measured by a LECO CS230 carbon/sulfur analyzer. For this purpose, samples were crushed to less than 100 mesh and then introduced to hydrochloric acid to remove the carbonates (Wang et al. 2016). In the next step, the samples are washed with distilled water and put in an oven at $70{ }^{\circ} \mathrm{C}$ until dried. Then, the TOC can be measured.

\subsection{Gas adsorption}

The samples were crushed to small grains less than $250 \mu \mathrm{m}$ in size. The crushed grains were degassed for at least $8 \mathrm{~h}$ at $110{ }^{\circ} \mathrm{C}$ to remove the bound water which is absorbed by clay minerals (Zou et al. 2017). Low-pressure nitrogen was used on a Micromeritics ${ }^{\circledR}$ Tristar II apparatus at $77 \mathrm{~K}$, while carbon dioxide adsorption data were obtained at $273 \mathrm{~K}$. The gas adsorption volume was measured through the relative equilibrium adsorption pressure changes. Density functional theory (DFT) was applied to analyze the pore size distribution (PSD) data from $\mathrm{N}_{2}$ adsorption (Do and Do 2003), while non-local density functional theory was used to analyze the carbon dioxide adsorption measurements (Amankwah and Schwarz 1995; Fan and Ziegler 1992).

\subsection{Multifractal analysis}

In order to describe the complexity of the pore structures, fractal theory, which was initially proposed by Mandelbrot (1977), has been widely used in pore structure analysis (Cai and Yu 2011; Wei et al. 2015). A fundamental characteristic of a fractal object is that the measured properties are a function of the scale of measurement. A good fractal model can give us more information about the pore structures (Xia et al. 2018). The fractal dimension characterizes the average properties but cannot describe the variations from the average (Gould and Vadakkan 2011), while multifractal analysis which decomposes the self-similar measures into intertwined fractal sets, characterized by their singularity strength, can provide more information about how the pores are distributed ( $\mathrm{Li}$ et al. 2012). In this paper, multifractal analysis was applied. The box-counting method was 
applied to analyze the pore size distribution data of the samples from the two different methods. In this procedure, a set of different boxes with equal length $(\varepsilon)$ are labeled by index $i$ where $N(\varepsilon)$ is defined as the total number of boxes with the size of $\varepsilon$ to cover the curve we analyzed. We will denote the section of the $i$ th box of size $\varepsilon$ as $u_{i}(\varepsilon)$. In this study, the relative pressure $\left(P / P_{0}\right)$ is equal and representing the length of the box which is $\varepsilon$ (Ferreiro et al. 2009, 2010). These boxes of length $\varepsilon$ were laid over the gas adsorption isotherm curve. Thus, the probability mass function for the $i$ th box can be calculated using the following equation:

$p_{i}(\varepsilon)=N_{i}(\varepsilon) / N_{\mathrm{T}}$,

where $N_{i}(\varepsilon)$ is the volume of adsorbed nitrogen for the $i$ th box. Thus, the total volume of gas adsorbed in the pores will be $N_{\mathrm{T}}$. Consequently, $p_{i}(\varepsilon)$ can be defined by an exponential function of the following form:

$p_{i}(\varepsilon) \sim \varepsilon^{\alpha_{i}}$

where $\alpha_{i}$ is the singularity exponent and represents the behavior of singularities of the system approaching to infinity as $\varepsilon$ gets closer to 0 (Feder 1988; Halsey et al. 1986). For multifractally distributed properties of intervals of size $\varepsilon, N(\varepsilon)$ increases when $\varepsilon$ decreases. This relationship can be presented in a power law mode of the following form:

$N_{\alpha}(\varepsilon) \sim \varepsilon^{-f(\alpha)}$,

where $N_{\alpha}(\varepsilon)$ is the number of boxes for which probability mass function of the $i$ th box, $p_{i}(\varepsilon)$, has singularity strength between $\alpha$ and $\alpha+\mathrm{d} \alpha$. Then, $f(\alpha)$ represents the spectrum of the fractal dimensions that characterizes the abundance in the set with $\alpha$ singularity. Subsequently, Chhabra and Jensen (1989) proposed Eqs. (4-6) to calculate $\alpha(q)$ and $f(\alpha)$ :

$\alpha(q) \propto\left[\sum_{i=1}^{N(\varepsilon)} u_{i}(q, \varepsilon) \times \ln p_{i}(\varepsilon)\right] / \ln (\varepsilon)$

$f(q) \propto\left[\sum_{i=1}^{N(\varepsilon)} u_{i}(q, \varepsilon) \times \ln u_{i}(q, \varepsilon)\right] / \ln (\varepsilon)$,

where

$u_{i}(q, \varepsilon)=\frac{p_{i}(\varepsilon)^{q}}{\sum_{i=1}^{N(\varepsilon)} p_{i}(\varepsilon)^{q}}$.

In the above equations, the fractal properties at different scales of the object can be expressed as $q$. In this study, $\alpha$ and $f(\alpha)$ were calculated through a linear regression using Eqs. (4) and (5) with $q$ varying from -10 to 10 for successive unit steps. Therefore, considering the application of multifractal analysis, a probability distribution function is defined as: $u(q, \varepsilon)=\sum_{i=1}^{N(\varepsilon)} p_{i}(\varepsilon)^{q} \sim \varepsilon^{\tau(q)}$,

where $\tau_{q}$ is the mass scaling function of order $q$ which is defined as:

$\tau(q)=\lim _{\varepsilon \rightarrow 0}\left[\ln \sum p_{i}(\varepsilon)^{q}\right] / \ln (1 / \varepsilon)$.

Thus, the generalized dimension $\left(D_{q}\right)$ which is related to $q$ can be expressed as:

$D_{q}=\tau(q) /(q-1)$.

While for $q=1, D_{q}$ will become:

$D_{1}=\lim _{\varepsilon \rightarrow 0}\left(\sum_{i=1}^{N(\varepsilon)} p_{i}(\varepsilon) \ln p_{i}(\varepsilon)\right) / \ln (\varepsilon)$.

\section{Results and discussion}

\subsection{Mineralogical compositions and TOC}

Table 1 summarizes the mineral assemblages and the TOC of our shale samples from the Longmaxi and Bakken Formations. The results show that the most abundant minerals in the samples from both formations are quartz and clay. Samples from the Bakken Formation have higher TOC than the samples from the Longmaxi Formation.

\subsection{Gas adsorption analysis}

\subsection{1 $\mathrm{N}_{2}$ adsorption}

Figures 1 and 2 represent $\mathrm{N}_{2}$ adsorption isotherms of the Longmaxi and Bakken Formation samples, respectively. It can be found from these figures that at very low relative pressures, the amount of adsorption of the gas depends on the micropore volume and their presence in the samples, while an increase in relative pressure initiates multilayer adsorption. The knee bend in Figs. 1 and 2 explains a transition from monolayer adsorption to multilayer adsorption. Additionally, a wider hysteresis loop can be found from Longmaxi samples compared to those from the Bakken Formation. The desorption curves for all samples were forced to coincide with the adsorption curve when the relative pressure was $0.4-0.6$ due to the tensile strength effect (Groen et al. 2003). One main difference between the isotherms of samples from the Bakken Formation and the Longmaxi Formation is the disappearance of the hysteresis loop at a specific value for the Bakken samples (Fig. 2). Moreover, the shape of the hysteresis loop can be related to the shape of the pores within the samples. Considering the 
Table 1 Mineralogical compositions and TOC contents of the samples

\begin{tabular}{lllllllll}
\hline Samples & \multirow{2}{*}{ Formation } & \multicolumn{3}{l}{ Mineral composition, wt\% } & \multicolumn{3}{c}{ TOC, wt\% } \\
\cline { 3 - 7 } & & Quartz & Feldspars & Calcite & Dolomite & Pyrite & Clay & \\
\hline Sample 1 & \multirow{2}{*}{ Longmaxi } & 57.81 & 10.69 & 3.81 & 3.52 & 3.85 & 20.33 & 5.42 \\
Sample 2 & & 52.91 & 8.44 & 5.62 & 5.92 & 2.21 & 24.89 & 3.03 \\
Sample 3 & 39.80 & 6.62 & 4.87 & 0.00 & 3.53 & 45.19 & 1.89 \\
Sample 4 & 33.62 & 5.27 & 0.00 & 1.70 & 0.00 & 59.41 & 0.58 \\
Sample5 & 38.91 & 11.46 & 3.08 & 3.61 & 2.03 & 40.92 & 1.41 \\
Sample 6 & Bakken & 65.20 & 3.30 & 0.00 & 0.00 & 2.83 & 27.00 & 13.54 \\
Sample 7 & & 54.80 & 0.00 & 0.00 & 8.80 & 8.07 & 28.60 & 20.17 \\
Sample 8 & 66.90 & 14.40 & 0.00 & 0.00 & 2.44 & 16.20 & 11.07 \\
Sample 9 & 35.30 & 14.40 & 0.00 & 0.00 & 8.80 & 41.50 & 16.93 \\
Sample 10 & 47.50 & 0.00 & 0.00 & 7.80 & 2.61 & 39.20 & 16.78 \\
\hline
\end{tabular}

shape of the hysteresis loop in Figs. 1 and 2, it can be seen that pores within the samples from the Longmaxi Formation are mostly "ink-bottle shaped," that is, with a wide body and a narrow neck, but pores from the Bakken Formation are mainly composed of cylindrical- and slit-shaped pores (Fig. 3) (Li et al. 2017a, b; Mendhe et al. 2017; Sing et al. 1985; Thommes et al. 2015).

This difference between the pore shapes of these two sets of rock samples can indicate the difference in the origin of the hysteresis. The form of the hysteresis curve of the Bakken samples can be attributed to the adsorption metastability. For cylindrical pores which are typically open-ended pores, the delayed condensation of the gas is due to the metastability of the absorbed multilayer. This is followed by the fact that in an assembly of cylindrical pores, the adsorption branch of the hysteresis loop is not in a thermodynamic equilibrium state. Therefore, if the pores are filled with a liquid-like condensate, thermodynamic equilibration will be established on the desorption branch of the curve instead (Landers et al. 2013; Monson 2012; Thommes and Cychosz 2014). Regarding the samples from the Longmaxi Formation, the desorption path can be dependent on the pore network and various forms of the pores being blocked due to the existence of "ink-bottle shaped" pores. In these types of pores, the wider end of the pores gains access to the external surface only through a narrower neck. These types of pores are filled and remain filled during the desorption process until the narrow necks are emptied at the lower vapor pressures (Landers et al. 2013; Monson 2012; Thommes and Cychosz 2014). Finally, none of the samples demonstrate a horizontal plateau as the relative pressure gets closer to 1 . This confirms that samples from both formations contain a good quantity of large macropores which cannot be characterized by the nitrogen gas adsorption technique (Schmitt et al. 2013).

\subsection{2 $\mathrm{CO}_{2}$ adsorption}

$\mathrm{CO}_{2}$ adsorption was utilized in this study specifically to quantify the micropores. Figure $4 \mathrm{a}, \mathrm{b}$ represents $\mathrm{CO}_{2}$ adsorption isotherms of samples from the Longmaxi and Bakken Formations, respectively. The $\mathrm{CO}_{2}$ adsorption curves for all the samples that were analyzed in this study illustrate that as the relative pressure increases, the adsorption quantity would increase rapidly and then followed by a slower increase when the relative pressure reaches the critical point.

\subsection{Pore parameter analysis}

Various pore parameters including the surface area and volume which are derived from $\mathrm{N}_{2}$ and $\mathrm{CO}_{2}$ adsorption for both groups of samples are given in Tables 2 and 3, respectively.

The results from $\mathrm{N}_{2}$ adsorption in Table 2 clarify that the surface area of the samples from the Longmaxi is 3 to 8 times of the surface area of the Bakken samples. Comparing these two sets of samples, the Longmaxi Formation with similar total pore volume has a much larger surface area which indicates that samples from the Longmaxi Formation have much smaller pore sizes. Pore parameters that are calculated from $\mathrm{CO}_{2}$ adsorption analysis in Table 3 illustrate that the micropore volume and surface area of the samples from the Longmaxi Formation are larger than that from the Bakken Formation. To provide a better explanation, Sample 2 is around 3 times larger than Sample 7 in micropore volume, and 5 times greater than Sample 7 in pore surface area. Thus, it can be concluded that the average pore size of Sample 2 which is from the Longmaxi Formation is smaller than the average pore size of Sample 7 from the Bakken Formation. It should be noted that $\mathrm{CO}_{2}$ can characterize the micropore parameters, while $\mathrm{N}_{2}$ adsorption can be used to derive the meso-macropore- 

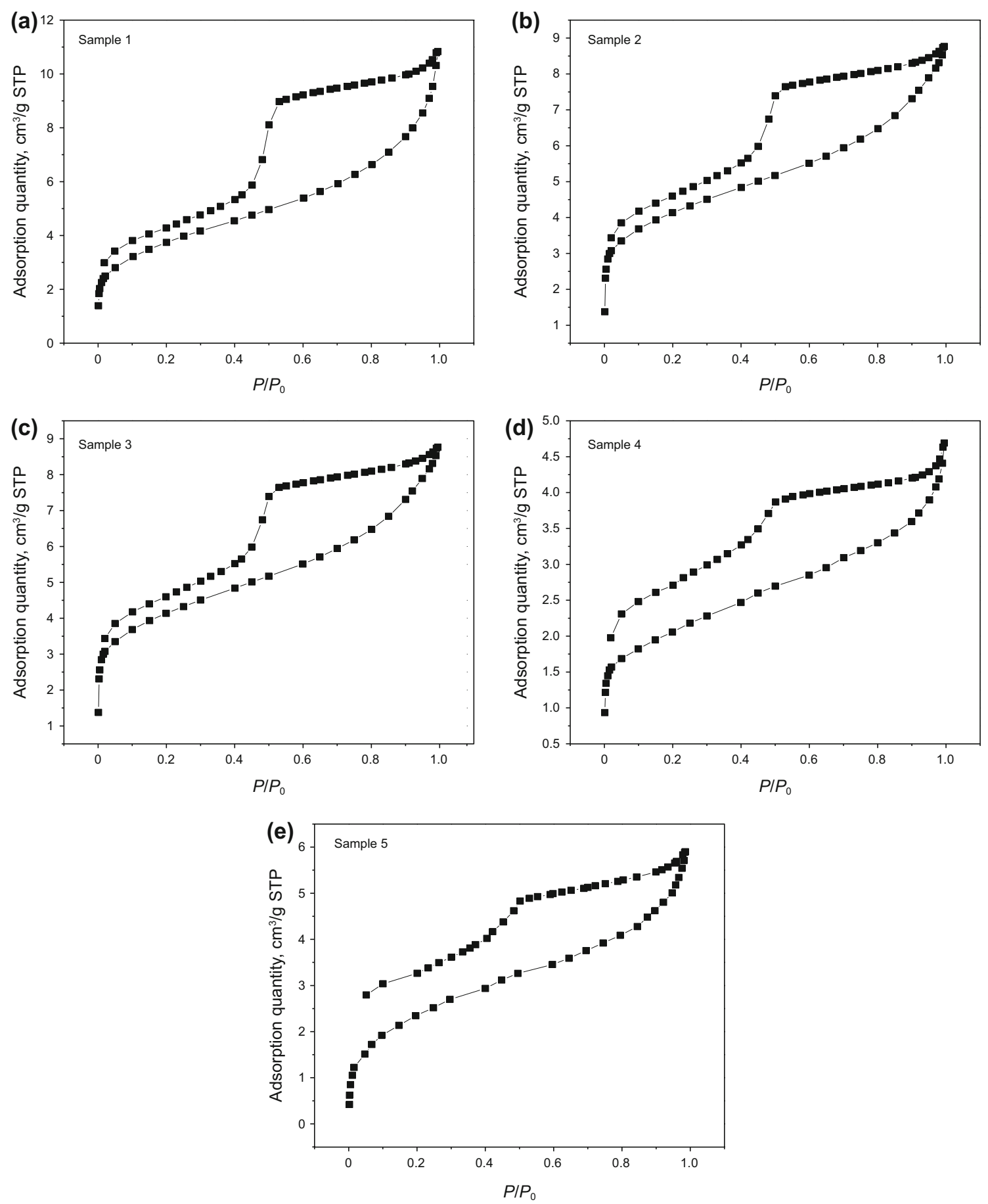

Fig. $1 \mathrm{~N}_{2}$ adsorption isotherms of the samples from the Longmaxi Formation

related information. From the above analysis, it can be deduced that the Longmaxi Formation has smaller average pore sizes compared to the Bakken Formation.

\subsection{Pore size distributions}

Figure 5 shows the micropore size distributions from $\mathrm{CO}_{2}$ adsorption. The curves in Fig. 5 all have multimodal characteristics. However, the pore clusters in the Longmaxi Formation are quite different in diameter from the pore clusters that are found in the Bakken Formation. The majority of the micropores in the Longmaxi Formation have an average pore size less than $1 \mathrm{~nm}$, while most of the micropores in the samples from the Bakken Formation have pore size larger than $1 \mathrm{~nm}$. 

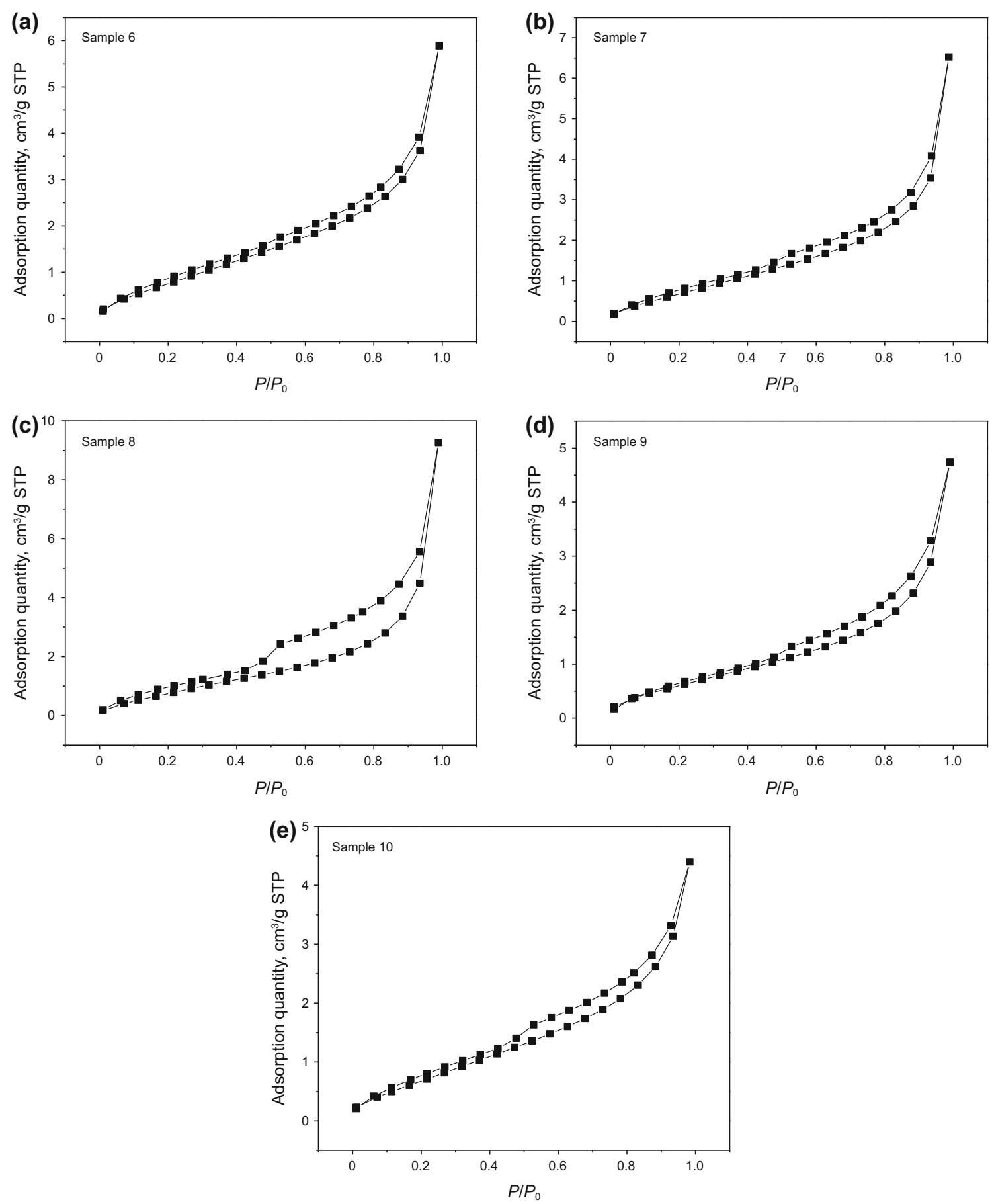

Fig. $2 \mathrm{~N}_{2}$ adsorption isotherms of the samples from the Bakken Formation

The meso-macropore size distributions that were derived from $\mathrm{N}_{2}$ gas adsorption are shown in Fig. 6. The deconvolution theory was applied to the experimental data in order to differentiate between various pore families based on the main peaks of the PSD curve. The detailed analysis procedure can be seen in our previous publication (Liu et al. 2017). Briefly, the pore size distributions of the shale samples can be regarded as the sum of different pore families $(J=1, \ldots, n)$ and each pore size family should fit a Gaussian/normal distribution (Liu et al. 2017; Sorelli et al. 2008; Ulm et al. 2007). Then, we minimize the difference between the data from the weighted model-phase probability distribution function (PDF) and the experimental $\mathrm{PDF}$ to derive the mean value and standard deviation of each pore family using the following equations: 

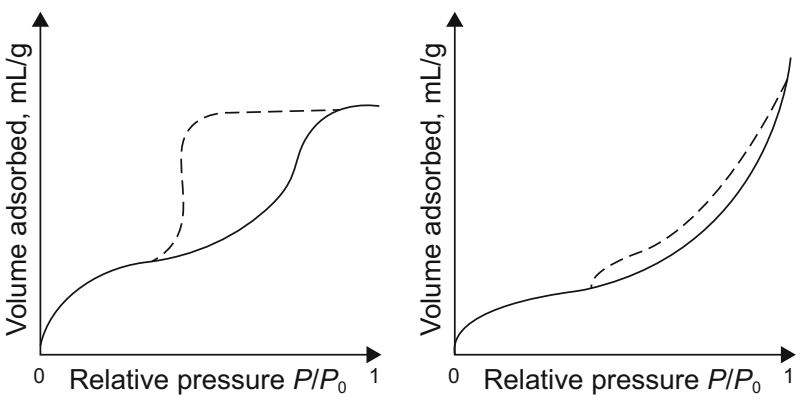

$\mathrm{H} 2$

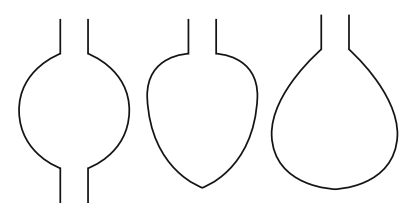

Ink-bottle-shaped pore

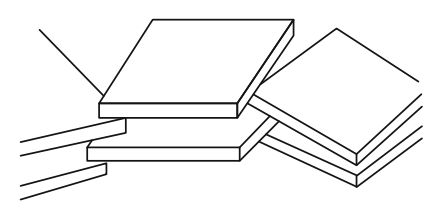

Slit-shaped pore

Fig. 3 Types of hysteresis loops and their corresponding pore shapes in this study (Groen et al. 2003; Thommes et al. 2015)

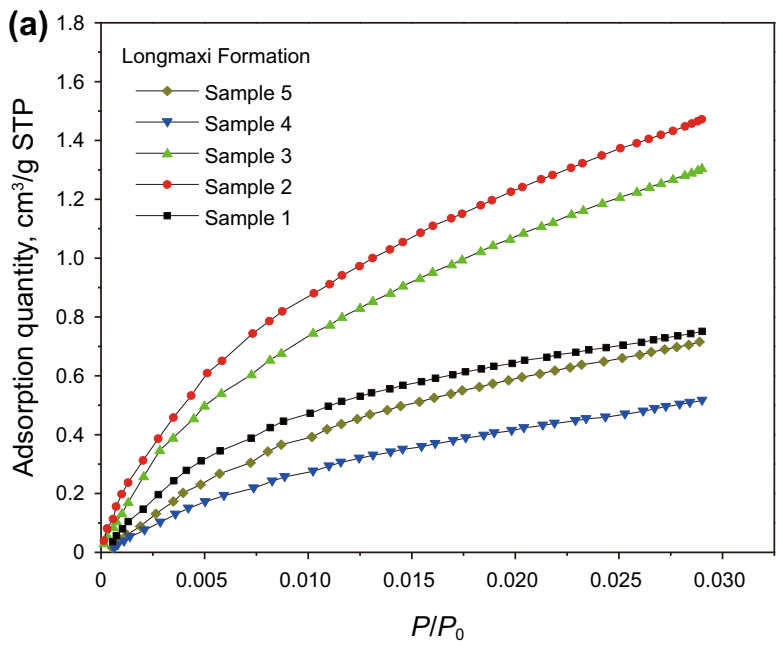

$P_{J}\left(x_{i}, U_{J}, S_{J}\right)=\frac{2}{\sqrt{2 \pi\left(S_{J}\right)^{2}}} \exp \left(\frac{-\left(x_{i}-\left(U_{J}\right)\right)^{2}}{2\left(S_{J}\right)^{2}}\right)$,

$\min \left[\sum^{m} \sum_{i=1}^{N}\left(\sum_{J}^{n} f_{J} P_{J}\left(x_{i}, U_{J}, S_{J}\right)-P_{x}\left(x_{i}\right)\right)^{2}\right]$

$\sum_{J=1}^{n} f_{J}=1$

$U_{J}+S_{J}<U_{J+1}+S_{J+1}$,

where $U_{J}$ and $S_{J}$ are the mean value and the standard deviation of pore size distributions of the phase $J=1$ to $n$. $f_{J}$ refers to the volume fractal of the $J$ th pore family to the total porosity. $P_{x}\left(x_{i}\right)$ is the measured value of the normalized frequency of the pore size $x_{i}$, and $m$ is the number of the intervals (bins).

The blue curve in Fig. 6 represents the experimental data, while the red dashed line shows the fitted curve after

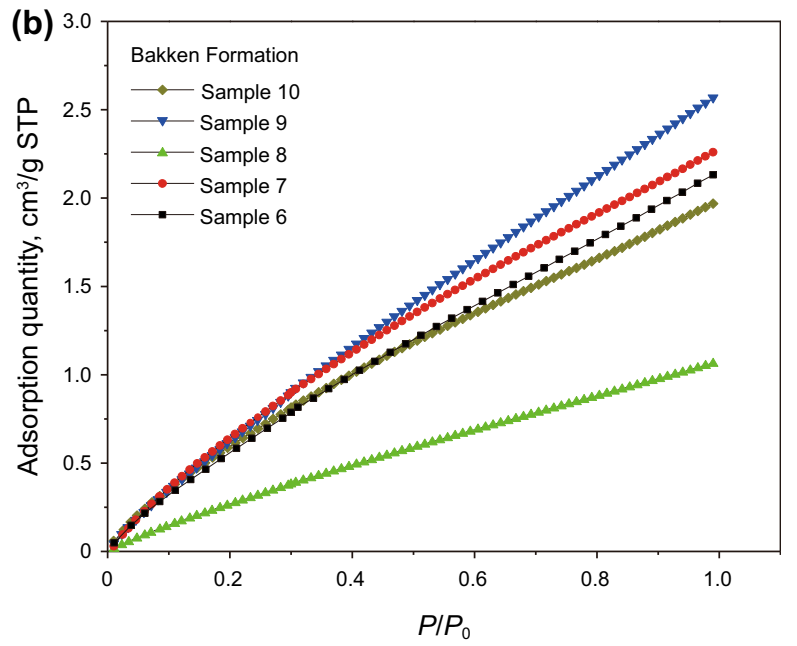

Fig. $4 \mathrm{CO}_{2}$ adsorption isotherms of the samples from the Longmaxi Formation (a) and Bakken Formation (b)

Table 2 Pore parameters of the samples from $\mathrm{N}_{2}$ adsorption

\begin{tabular}{lllll}
\hline Sample & Formation & Surface area, $\mathrm{m}^{2} / \mathrm{g}$ & \multicolumn{2}{l}{ Pore volume, $10^{-2} \mathrm{~cm}^{3} / \mathrm{g}$} \\
\cline { 3 - 4 } & & Mesopores & Macropores \\
\hline Sample 1 & Longmaxi & 12.86 & 1.26 & 0.09 \\
Sample 2 & 16.23 & 0.95 & 0.03 \\
Sample 3 & 16.44 & 0.76 & 0.02 \\
Sample 4 & 8.60 & 0.47 & 0.03 \\
Sample 5 & & 6.21 & 0.57 & 0.03 \\
Sample 6 & Bakken & 1.78 & 0.77 & 0.12 \\
Sample 7 & & 1.66 & 0.85 & 0.13 \\
Sample 8 & 1.86 & 1.18 & 0.23 \\
Sample 9 & 1.35 & 0.62 & 0.10 \\
Sample 10 & & 1.55 & 0.61 & 0.04 \\
\hline
\end{tabular}



samples from $\mathrm{CO}_{2}$ adsorption
Table 3 Pore parameters of the

\begin{tabular}{llll}
\hline Sample & Formation & Micropore area, $\mathrm{m}^{2} / \mathrm{g}$ & Pore volume, $10^{-2} \mathrm{~cm}^{3} / \mathrm{g}$ \\
\hline Sample 1 & Longmaxi & 8.09 & 0.30 \\
Sample 2 & & 15.30 & 0.50 \\
Sample 3 & 13.74 & 0.40 \\
Sample 4 & 5.69 & 0.20 \\
Sample 5 & 7.70 & 0.30 \\
Sample 6 & Bakken & 2.40 & 0.15 \\
Sample 7 & 3.00 & 0.18 \\
Sample 8 & 1.19 & 0.08 \\
Sample 9 & 2.64 & 0.17 \\
Sample 10 & & 2.61 & 0.16 \\
\hline
\end{tabular}
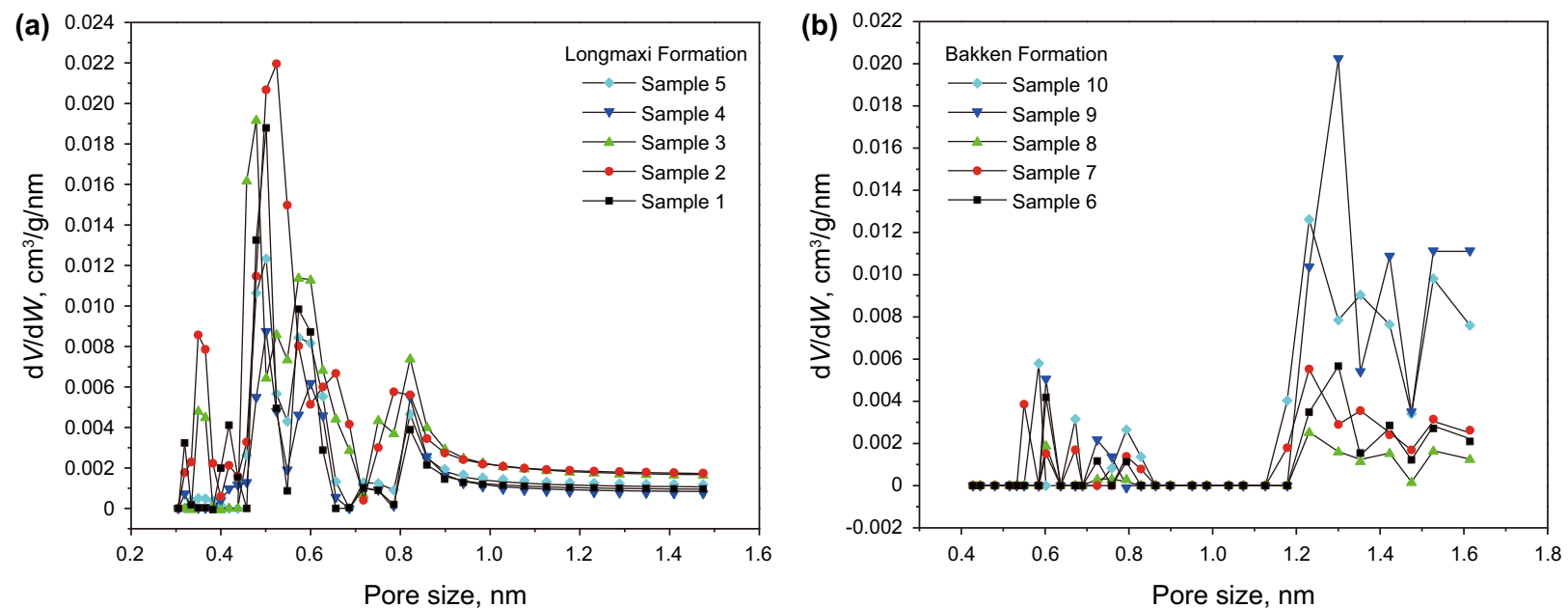

Fig. 5 Micropore size distributions from $\mathrm{CO}_{2}$ adsorption

the deconvolution was applied. Meso-macropores of the samples from the Longmaxi Formation can be divided into 3 separate pore clusters, while the meso-macropores of the samples from the Bakken can be divided into 5 distinguished pore families. The mean pore size of all three pore families of the Longmaxi Formation is less than $20 \mathrm{~nm}$, whereas in the samples from the Bakken Formation, three pore clusters (Family 1,2 and 3) have a mean pore size diameter less than $20 \mathrm{~nm}$ and the remaining two clusters (Family 4 and 5) have a mean pore size diameter bigger than $20 \mathrm{~nm}$. The detailed results from the deconvolution process are summarized in Table 4 which illustrates that samples from the Longmaxi and Bakken Formation have approximately similar mean pore size diameters for Family 1 (around $3 \mathrm{~nm}$ ), Family 2 (around $4.8 \mathrm{~nm}$ ) and Family 3 (around $10 \mathrm{~nm}$ ). In summary, both sets of samples have comparable pore clusters when the pore size diameter varies between 2 and $20 \mathrm{~nm}$, while there exist two additional pore clusters: Family 4 and Family 5 in the Bakken Formation with average pore size diameter around 24 and $35 \mathrm{~nm}$, respectively.

\subsection{Fractal analysis}

The fractal theory is a very practical tool to characterize the overall structure of the pore network in any porous medium. Through this method, we can extract the fractal dimensions from the dataset and then describe the selfsimilar geometric irregularities of the pore space at different scales (Tang et al. 2010). In this study, the multifractal method was employed to analyze and compare the pore structures of the samples from the Longmaxi and Bakken Formations.

\subsubsection{Multifractal analysis of $\mathrm{CO}_{2}$ adsorption}

Figure 7 represents the correlations between $D_{q}$ and $q$ of every studied sample. All the curves follow a monotonic decrease as $q$ increases (i.e., $D_{0}>D_{1}>D_{2}$ ) which confirms that pore size distributions (PSD) from $\mathrm{CO}_{2}$ adsorption have a multifractal behavior. $D_{0}, D_{1}$ and $D_{2}$ are different parameters that are commonly used for multifractal analysis. $D_{0}$ is known as the capacity dimension 

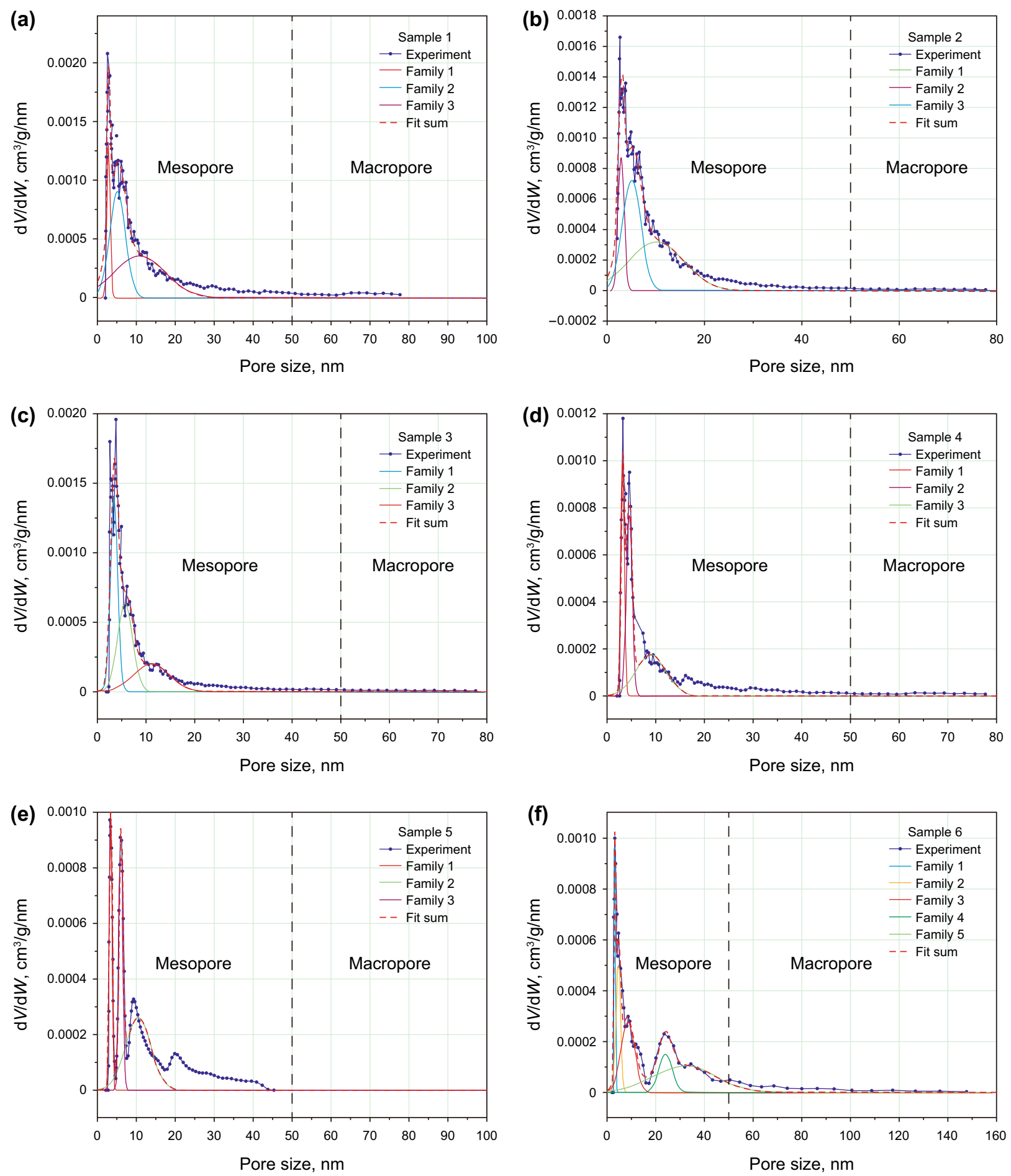

Fig. 6 Meso-macropore size distributions from $\mathrm{N}_{2}$ adsorption

which is the distribution of average values of the analyzed structure. $D_{0}$ is a measure of the complexity of the pore structures in a porous medium. $D_{1}$ is the information dimension and $D_{2}$ is the correlation dimension ( $\mathrm{Li}$ et al. 2012), while $D_{0}-D_{1}$ represents the concentration degree of the pore size distribution along the pore size intervals $(\mathrm{Li}$

et al. 2015; Song et al. 2018). The data in Table 5 indicate that the samples from the Longmaxi Formation have larger $D_{0}-D_{1}$ values, which means they have a more concentrated pore size distribution. The multifractal spectrum of all samples is plotted in Fig. 8. Similar to $D_{q}, \alpha_{q}$ also decreases as $q$ increases. This relationship enables us to 

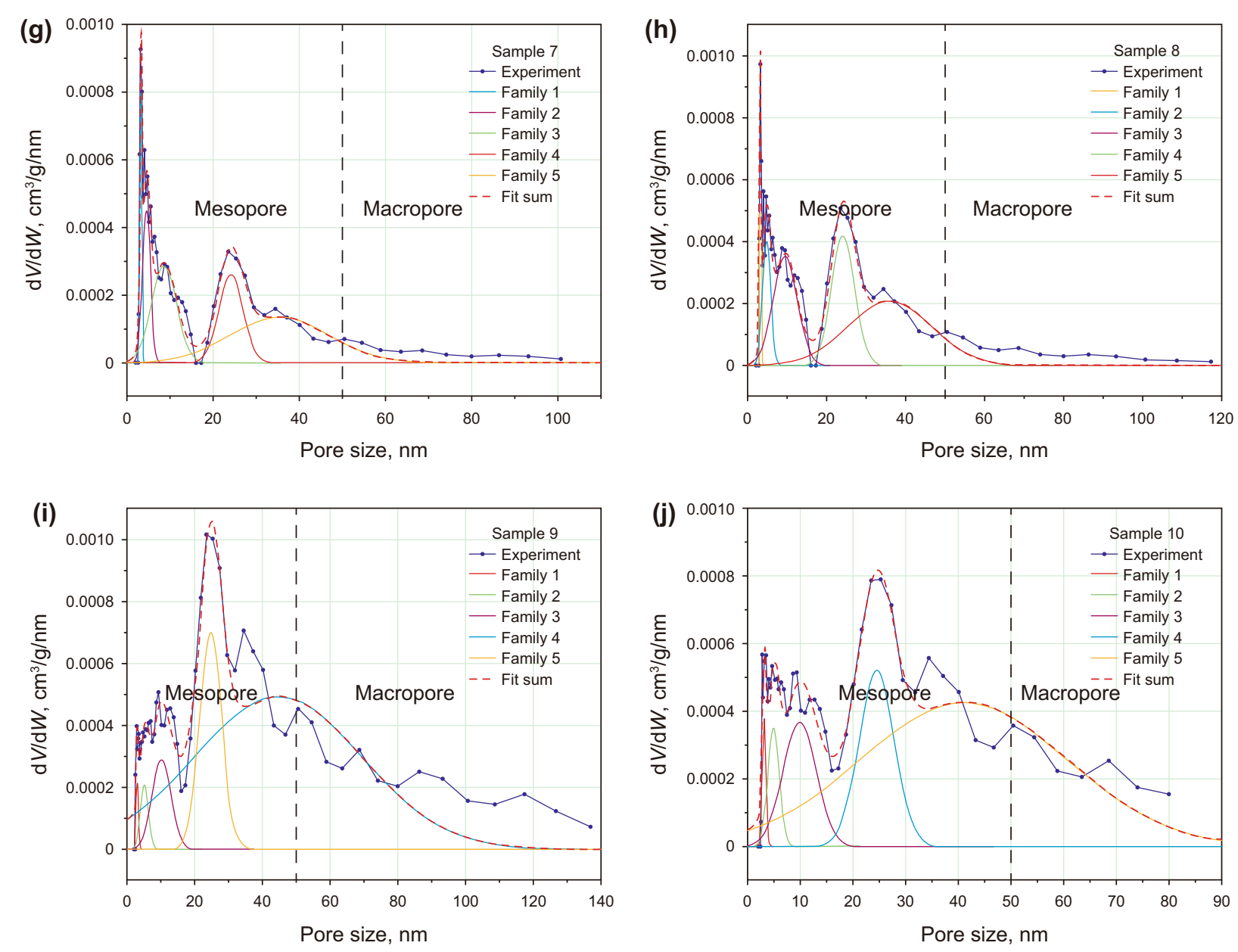

Fig. 6 continued

Table 4 Deconvolution results of the meso-macropores from $\mathrm{N}_{2}$ adsorption

\begin{tabular}{|c|c|c|c|c|c|c|}
\hline \multirow[t]{2}{*}{ Sample } & \multirow[t]{2}{*}{ Formation } & \multicolumn{5}{|c|}{ Mean value, $\mathrm{nm}$} \\
\hline & & Family 1 & Family 2 & Family 3 & Family 4 & Family 5 \\
\hline Sample 1 & Longmaxi & $2.85 \pm 0.03$ & $5.18 \pm 0.27$ & $10.86 \pm 4.48$ & - & - \\
\hline Sample 2 & & $2.91 \pm 0.04$ & $5.01 \pm 0.44$ & $10.11 \pm 3.78$ & - & - \\
\hline Sample 3 & & $3.44 \pm 0.09$ & $5.68 \pm 0.90$ & $11.12 \pm 4.46$ & - & - \\
\hline Sample 4 & & $3.26 \pm 0.03$ & $4.51 \pm 0.04$ & $8.97 \pm 0.71$ & - & - \\
\hline Sample 5 & & $3.43 \pm 0.02$ & $6.04 \pm 0.03$ & $10.43 \pm 0.35$ & - & - \\
\hline Sample 6 & Bakken & $3.16 \pm 0.03$ & $4.52 \pm 0.18$ & $8.45 \pm 0.92$ & $23.88 \pm 1.19$ & $31.64 \pm 7.24$ \\
\hline Sample 7 & & $3.21 \pm 0.02$ & $4.46 \pm 0.12$ & $8.51 \pm 0.61$ & $24.08 \pm 0.54$ & $35.31 \pm 4.73$ \\
\hline Sample 8 & & $3.22 \pm 0.02$ & $4.76 \pm 0.13$ & $9.46 \pm 0.56$ & $24.03 \pm 0.39$ & $35.93 \pm 4.45$ \\
\hline Sample 9 & & $3.06 \pm 0.16$ & $5.08 \pm 0.57$ & $10.08 \pm 0.99$ & $24.72 \pm 0.40$ & $44.54 \pm 3.98$ \\
\hline Sample 10 & & $3.14 \pm 0.08$ & $4.89 \pm 0.30$ & $9.84 \pm 0.79$ & $24.42 \pm 0.47$ & $41.03 \pm 4.40$ \\
\hline
\end{tabular}

calculate the fluctuations of maximum probability $\left(\alpha_{\max }\right)$ and minimum probability $\left(\alpha_{\min }\right)$ of pore size distributions (Costa and Nogueira 2015). Hence, the related extension of the singularity length $(\Delta \alpha)$, which can denote the heterogeneity that exists in pore size distributions, can be quantified. Table 5 is the summary of multifractal analysis parameters from $\mathrm{CO}_{2}$ adsorption data. From this table, it is understood that the samples from the Longmaxi Formation have larger $\Delta \alpha$ than the samples from the Bakken Formation, which can be translated as the pore size distribution of 

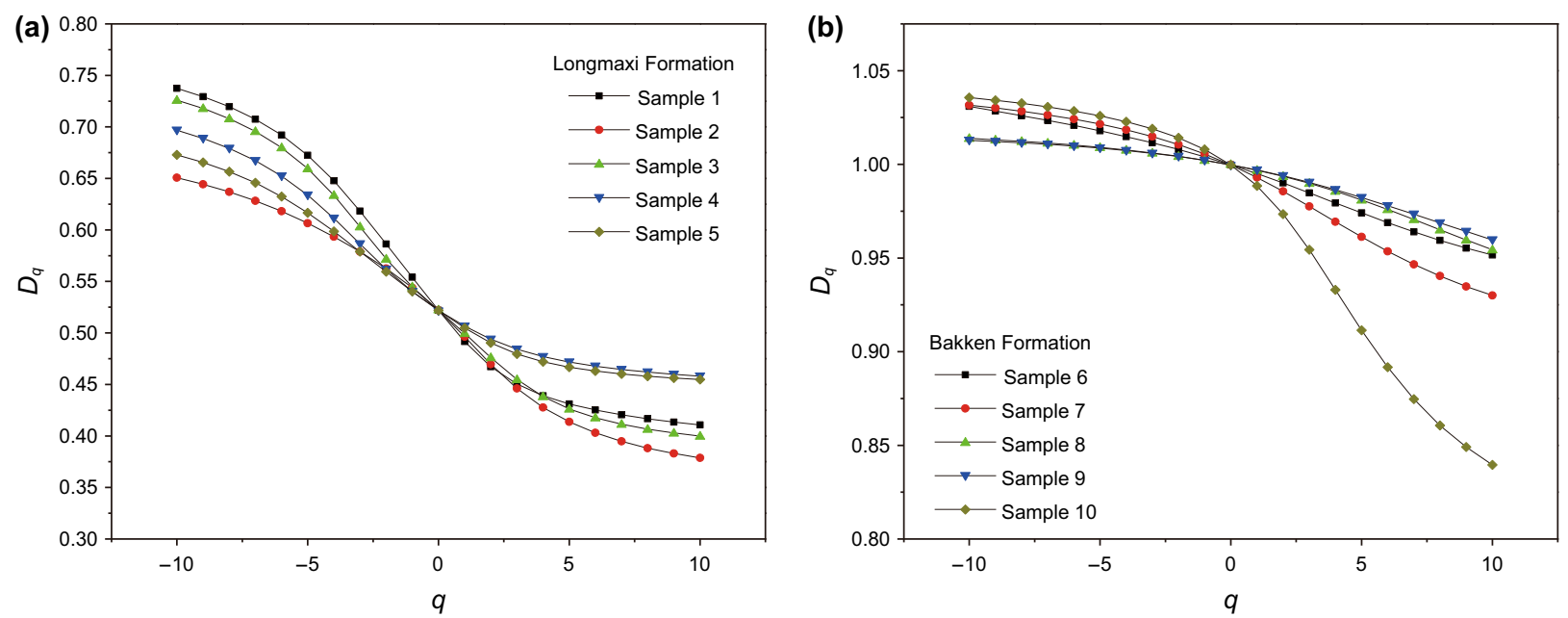

Fig. 7 Correlations between the generalized dimensions and the exponent $\left(\mathrm{CO}_{2}\right.$ adsorption)

Table 5 Multifractal analysis results from $\mathrm{CO}_{2}$ adsorption

\begin{tabular}{llllllll}
\hline Sample & $D_{0}$ & $D_{1}$ & $D_{2}$ & $D_{0}-D_{1}$ & $\alpha_{\max }$ & $\alpha_{\min }$ & $\Delta \alpha$ \\
\hline Sample 1 & 0.522 & 0.492 & 0.467 & 0.030 & 0.817 & 0.388 & 0.429 \\
Sample 2 & 0.546 & 0.496 & 0.444 & 0.049 & 0.716 & 0.344 & 0.372 \\
Sample 3 & 0.500 & 0.476 & 0.455 & 0.023 & 0.806 & 0.376 & 0.430 \\
Sample 4 & 0.522 & 0.496 & 0.470 & 0.026 & 0.776 & 0.443 & 0.333 \\
Sample 5 & 0.522 & 0.492 & 0.467 & 0.030 & 0.817 & 0.388 & 0.429 \\
Sample 6 & 1.000 & 0.995 & 0.990 & 0.005 & 1.058 & 0.920 & 0.137 \\
Sample 7 & 1.000 & 0.993 & 0.986 & 0.007 & 1.047 & 0.889 & 0.158 \\
Sample 8 & 1.000 & 0.997 & 0.994 & 0.003 & 1.022 & 0.908 & 0.114 \\
Sample 9 & 1.000 & 0.997 & 0.994 & 0.003 & 1.019 & 0.920 & 0.098 \\
Sample 10 & 1.000 & 0.989 & 0.973 & 0.011 & 1.050 & 0.762 & 0.288 \\
\hline
\end{tabular}

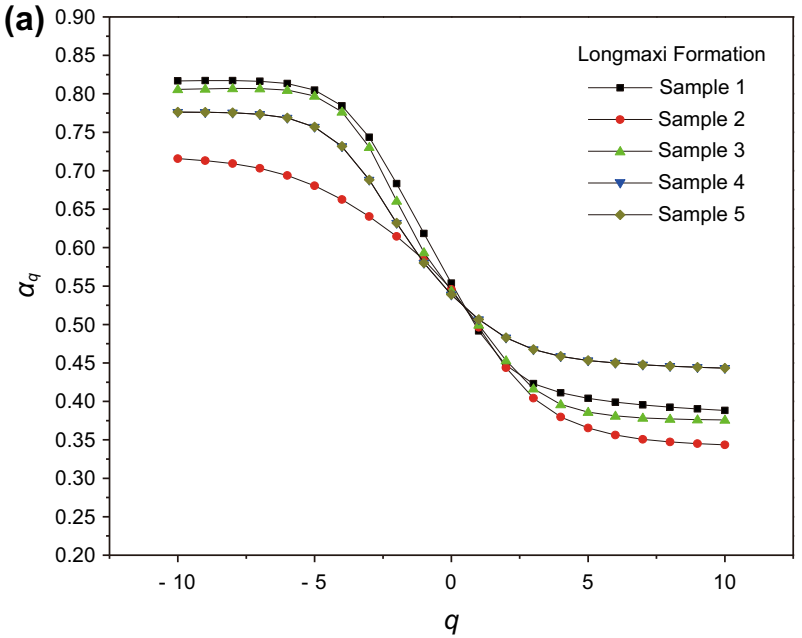

the Longmaxi samples is more heterogeneous in nature compared to that of the Bakken samples.

\subsubsection{Multifractal analysis of $\mathrm{N}_{2}$ adsorption}

The generalized dimensions and the singularity of all samples from $\mathrm{N}_{2}$ adsorption are shown in Figs. 9 and 10, respectively. From this figure, it is seen that $D_{q}$ and $\alpha_{q}$ will both decrease as $q$ increases, meaning that PSD curves from $\mathrm{N}_{2}$ adsorption can be described via a multifractal behavior. The Hurst exponent $(H)$ which is defined as $\left(D_{2}+1\right) / 2$ can be used to characterize pore connectivity (Riedi et al. 1999). Considering the results in Table 6, the Longmaxi samples have slightly higher average $H$ values than the Bakken samples which infers that pore connectivity in these samples is slightly superior to the samples

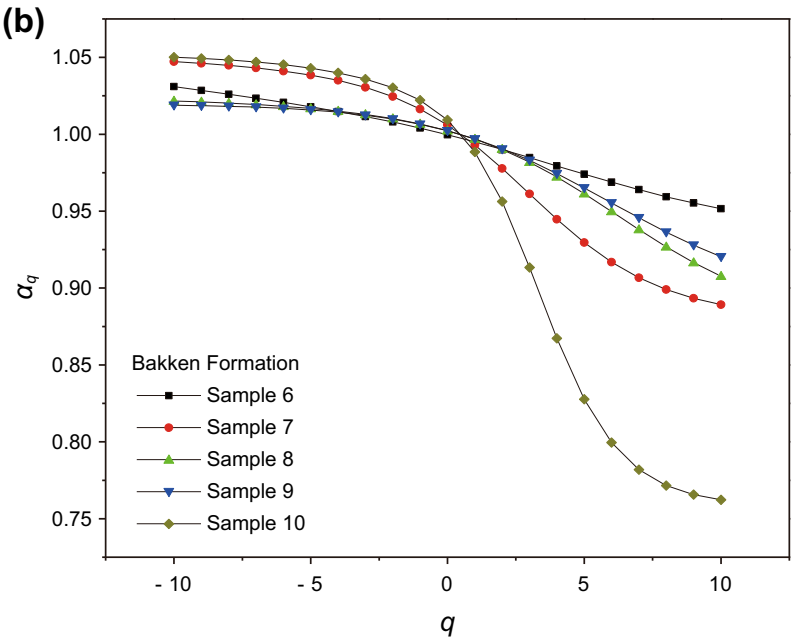

Fig. 8 Correlations between the singularity strength and the exponent $\left(\mathrm{CO}_{2}\right.$ adsorption) 

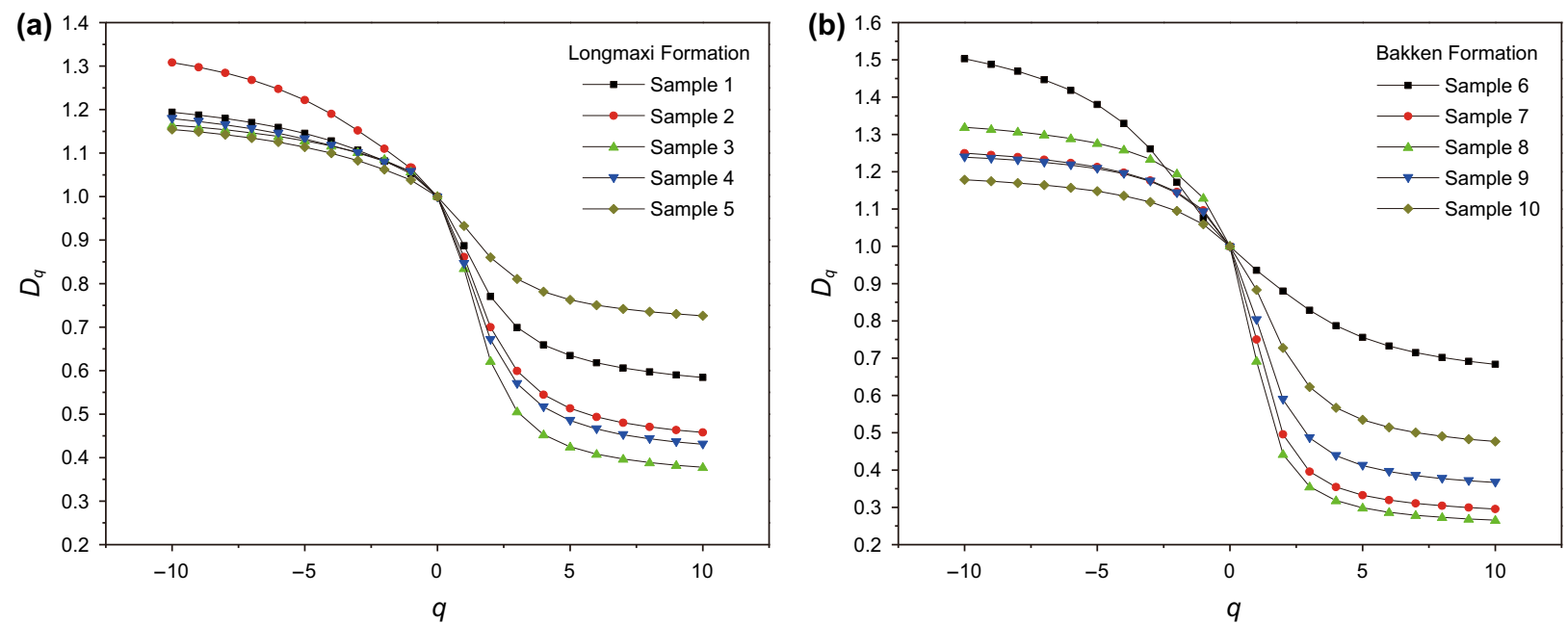

Fig. 9 Correlations between the generalized dimensions and the exponent $\left(\mathrm{N}_{2}\right.$ adsorption)
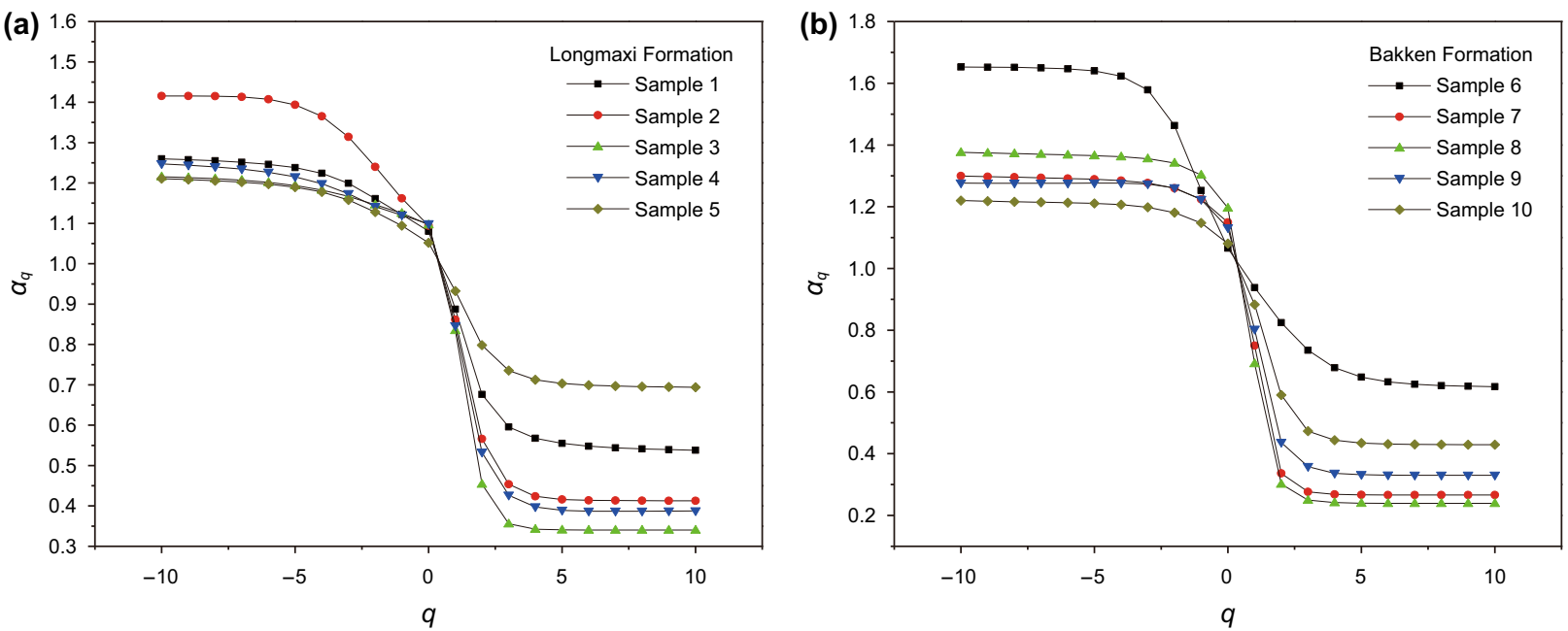

Fig. 10 Correlations between the singularity strength and the exponent ( $\mathrm{N}_{2}$ adsorption)

Table 6 Multifractal analysis results from $\mathrm{N}_{2}$ adsorption

\begin{tabular}{lllllllll}
\hline Sample & $D_{0}$ & $D_{1}$ & $D_{2}$ & $D_{0}-D_{1}$ & $\alpha_{\max }$ & $\alpha_{\min }$ & $\Delta \alpha$ & $H$ \\
\hline Sample 1 & 1.000 & 0.887 & 0.770 & 0.112 & 1.260 & 0.538 & 0.722 & 0.885 \\
Sample 2 & 1.000 & 0.861 & 0.700 & 0.138 & 1.416 & 0.413 & 1.003 & 0.850 \\
Sample 3 & 1.000 & 0.835 & 0.622 & 0.165 & 1.215 & 0.340 & 0.875 & 0.811 \\
Sample 4 & 1.000 & 0.846 & 0.671 & 0.154 & 1.247 & 0.388 & 0.860 & 0.836 \\
Sample 5 & 1.000 & 0.887 & 0.770 & 0.112 & 1.260 & 0.538 & 0.722 & 0.885 \\
Sample 6 & 1.000 & 0.936 & 0.880 & 0.064 & 1.653 & 0.617 & 1.035 & 0.940 \\
Sample 7 & 1.000 & 0.750 & 0.496 & 0.250 & 1.300 & 0.266 & 1.033 & 0.748 \\
Sample 8 & 1.000 & 0.692 & 0.442 & 0.307 & 1.376 & 0.239 & 1.137 & 0.721 \\
Sample 9 & 1.000 & 0.803 & 0.589 & 0.197 & 1.277 & 0.330 & 0.947 & 0.795 \\
Sample 10 & 1.000 & 0.883 & 0.727 & 0.117 & 1.220 & 0.429 & 0.791 & 0.864 \\
\hline
\end{tabular}

from the Bakken Formation. The average related extension of the singularity length $(\Delta \alpha)$ of the samples from the Bakken Formation is larger than the samples from the
Longmaxi Formation, indicating that pore size distributions (meso-macropores) of the samples from the Bakken 
Formation are more heterogeneous compared to that of the samples from the Longmaxi Formation.

It was stated previously that $\mathrm{CO}_{2}$ adsorption can quantify micropores and $\mathrm{N}_{2}$ adsorption can characterize the structures of meso-macropores. The multifractal analysis from $\mathrm{CO}_{2}$ adsorption can provide us with the information about the micropore heterogeneity, while the multifractal analysis from $\mathrm{N}_{2}$ adsorption can reveal the meso-macropore heterogeneity. The $\Delta \alpha$ derived from $\mathrm{CO}_{2}$ adsorption is smaller than the $\Delta \alpha$ from $\mathrm{N}_{2}$ adsorption, reflecting that meso-macropores are more heterogeneous than micropores. An overall comparison among all samples regarding their heterogeneity showed that the Longmaxi Formation has greater micropore heterogeneity, whereas the Bakken Formation has more significant meso-macropore heterogeneity.

\subsection{The influence of the organic matter and mineral compositions (PLS analysis)}

The compositions of the shale rock (including the organic matter and the minerals) could affect the pore structures of shale samples. In order to avoid eliminating the influence of one rock composition on the other based on the bivariate plots, when in fact the parameter may exert a significant influence when it is joined by another independent parameter, partial least squares (PLS) regression was applied (Liu et al. 2017). PLS regression is a statistical method that shows some relation to principal components regression. Instead of finding hyperplanes of maximum variance between the response and independent variables, this method could find a linear regression model by projecting the predicted variables and the observable variables to a new space (Wold et al. 2001). In this part, the influence of the rock compositions of the Longmaxi and Bakken shale samples on the pore structures will be studied separately. The pore structures (micropore volume, mesopore volume, macropore volume, micropore surface area, mesopore surface area, macropore surface area, micropore heterogeneity and meso-macropore heterogeneity) will be input as the dependent parameters, while the rock compositions (minerals and organic matter) will be regarded as the independent parameters. Tables 7 and 8 show the PLS analysis results of the Longmaxi shale samples and Bakken shale samples, respectively.

Table 7 shows that for the micropore information of the Longmaxi samples, all the minerals, except clay minerals, have a positive effect on the micropore volume and micropore surface area. The more the organic matter in the samples, the larger the micropore volume and micropore surface area. The positive impact of the organic matter on the micropore structures (pore volume and pore surface area) indicates the existence of abundant micropores in the organic matter. Organic matter and pyrite are the two major compositions that affect the micropore volume and micropore area. The effect of the minerals and organic matter on the mesopore structures and macropore structures are the same which is similar to their influence on the micropore structures. As the minerals (except clay minerals) increase, the pore area (mesopore area and macropore area) and the pore volume (mesopore volume and macropore volume) will increase. The minerals (except clay minerals) have a positive effect on the micropore heterogeneity while having negative effect on the meso-macropore heterogeneity. Overall, various sizes of pores from micropore size to macropore size exist in the Longmaxi samples which can be proved by the SEM images (Fig. 11).

For the micropore information of the Bakken shale samples, quartz and feldspar have a negative influence on the micropore volume and micropore area, while the rest of the rock compositions have a positive effect on the micropore structures. Among all the compositions, organic matter affects the micropores the most. For the mesopore and macropore structures, the increase in the quartz and feldspar can increase the mesopore volume, mesopore area, macropore area and macropore volume which can indicate the existence of the meso-macropores in these two minerals. The organic matter in Bakken shale samples can

Table 7 PLS analysis results of Longmaxi samples

\begin{tabular}{|c|c|c|c|c|c|c|c|c|}
\hline Variable & $\begin{array}{l}\text { Micropore } \\
\text { volume }\end{array}$ & $\begin{array}{l}\text { Micropore } \\
\text { area }\end{array}$ & $\begin{array}{l}\text { Mesopore } \\
\text { volume }\end{array}$ & $\begin{array}{l}\text { Mesopore } \\
\text { area }\end{array}$ & $\begin{array}{l}\text { Macropore } \\
\text { volume }\end{array}$ & $\begin{array}{l}\text { Macropore } \\
\text { area }\end{array}$ & $\begin{array}{l}\text { Micropore } \\
\text { heterogeneity }\end{array}$ & $\begin{array}{l}\text { Meso-macropore } \\
\text { heterogeneity }\end{array}$ \\
\hline Intercept & 0.2196 & 6.7152 & 0.2670 & 2.0046 & 0.0073 & 0.0071 & 0.3508 & 0.8573 \\
\hline Quartz & 0.0015 & 0.0422 & 0.0067 & 0.0427 & 0.0004 & 0.0002 & 0.0006 & -0.0003 \\
\hline Feldspars & 0.0032 & 0.0889 & 0.0140 & 0.0899 & 0.0009 & 0.0005 & 0.0013 & -0.0005 \\
\hline Calcite & 0.0048 & 0.1359 & 0.0215 & 0.1374 & 0.0013 & 0.0008 & 0.0019 & -0.0008 \\
\hline Dolomite & 0.0023 & 0.0637 & 0.0100 & 0.0644 & 0.0006 & 0.0004 & 0.0009 & -0.0004 \\
\hline Pyrite & 0.0088 & 0.2489 & 0.0393 & 0.2518 & 0.0024 & 0.0014 & 0.0035 & -0.0015 \\
\hline Clay & -0.0009 & -0.0243 & 0.0038 & 0.0245 & 0.0002 & 0.0001 & -0.0003 & 0.0001 \\
\hline TOC & 0.0077 & 0.2152 & 0.0340 & 0.2177 & 0.0021 & 0.0013 & 0.0030 & -0.0013 \\
\hline
\end{tabular}


Table 8 PLS analysis results of Bakken samples

\begin{tabular}{lcrrrrrrr}
\hline Variable & $\begin{array}{l}\text { Micropore } \\
\text { volume }\end{array}$ & \multicolumn{1}{l}{$\begin{array}{l}\text { Micropore } \\
\text { area }\end{array}$} & $\begin{array}{l}\text { Mesopore } \\
\text { volume }\end{array}$ & $\begin{array}{l}\text { Mesopore } \\
\text { area }\end{array}$ & $\begin{array}{l}\text { Macropore } \\
\text { volume }\end{array}$ & $\begin{array}{l}\text { Macropore } \\
\text { area }\end{array}$ & $\begin{array}{l}\text { Micropore } \\
\text { heterogeneity }\end{array}$ & $\begin{array}{l}\text { Meso-macropore } \\
\text { heterogeneity }\end{array}$ \\
\hline Intercept & 0.1023 & 1.5716 & 1.0448 & 1.8036 & 0.1951 & 0.0533 & 0.1169 & 1.1094 \\
Quartz & -0.0008 & -0.0138 & 0.0041 & 0.0034 & 0.0012 & 0.0003 & -0.0007 & 0.0021 \\
Feldspars & -0.0011 & -0.0184 & 0.0055 & 0.0045 & 0.0016 & 0.0004 & -0.0010 & 0.0028 \\
Dolomite & 0.0017 & 0.0290 & -0.0087 & -0.0071 & -0.0026 & -0.0007 & 0.0015 & -0.0044 \\
Pyrite & 0.0018 & 0.0306 & -0.0092 & -0.0075 & -0.0027 & -0.0007 & 0.0016 & -0.0046 \\
Clay & 0.0014 & 0.0242 & -0.0073 & -0.0060 & -0.0022 & -0.0006 & 0.0013 & -0.0037 \\
TOC & 0.0026 & 0.0450 & -0.0135 & -0.0111 & -0.0040 & -0.0011 & 0.0024 & -0.0068 \\
\hline
\end{tabular}
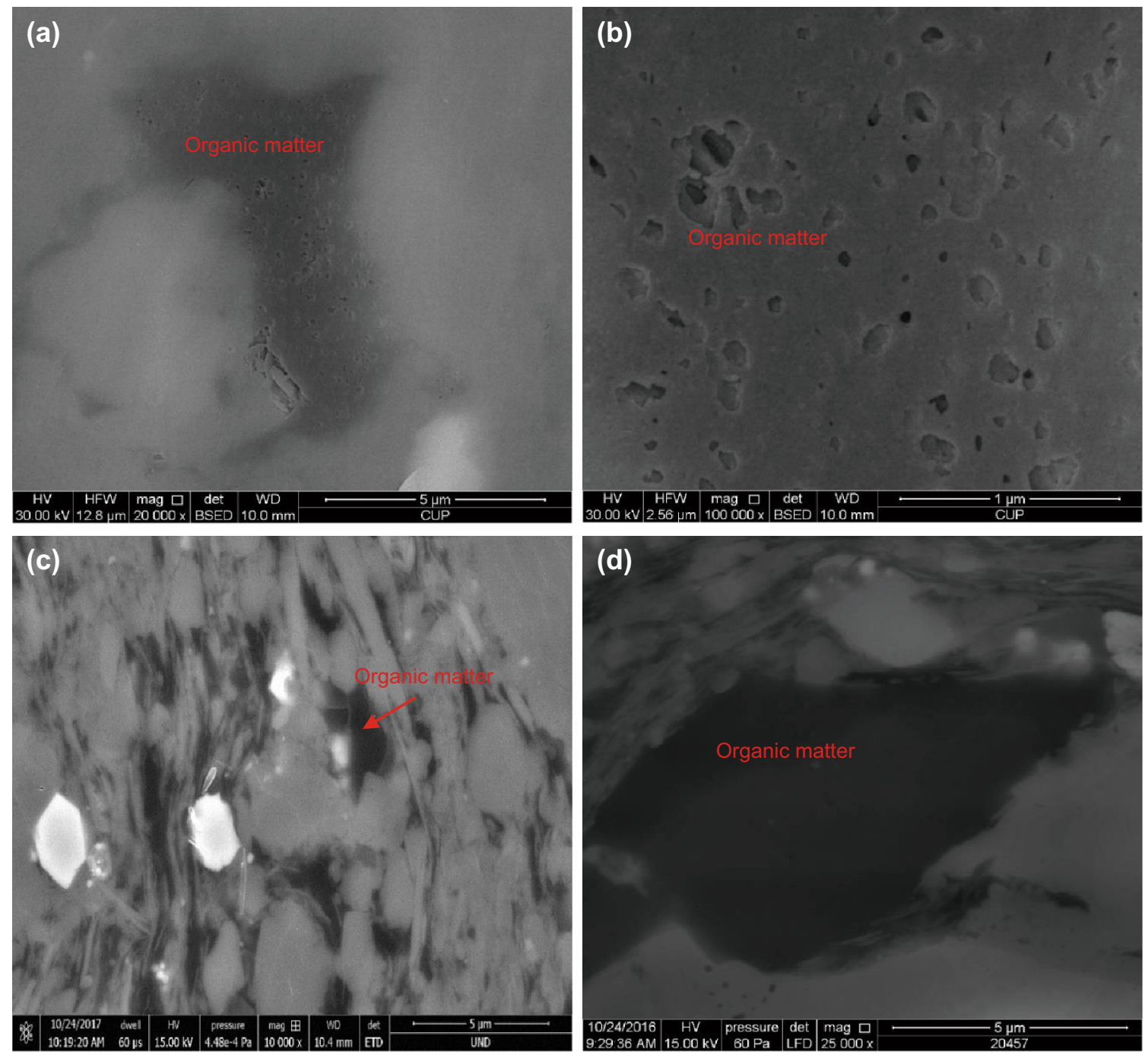

Fig. 11 SEM images of the organic matter $(\mathrm{OM})$ of the shale samples. $\mathbf{a}$ and $\mathbf{b}$ are the samples from the Longmaxi Formation, $\mathbf{c}$ and $\mathbf{d}$ are the samples from the Bakken Formation

increase the micropore surface area and micropore volume while reducing the meso-macropore surface area and volume, demonstrating that the main pores in the organic matter in the Bakken shale are micropores. Quartz and feldspar can decrease the micropore heterogeneity while increasing the meso-macropore heterogeneity. Clay minerals and organic matter can increase the micropore 
heterogeneity while reducing the meso-macropore heterogeneity.

Overall, the PLS analysis of the influence of the minerals on the pore structures of Longmaxi and Bakken shale samples shows that organic matter and pyrite are the two main compositions that affect the pore structures. Quartz and feldspar in Longmaxi samples can increase the micropore heterogeneity and reduce the meso-macropore heterogeneity, while these two minerals in Bakken shale samples could reduce the micropore heterogeneity and increase the meso-macropore heterogeneity. Organic pores with various sizes (micropore, mesopore and macropore) exist in Longmaxi samples, while the organic matter in Bakken samples mainly hosts micropores.

Figure 11 shows FE-SEM images of the samples in this study. It can be seen that a variety of pore sizes exist in the Longmaxi organic matter. We were not able to detect any pores of any size in the organic matter in the Bakken samples (the resolution limitation of the SEM is $9 \mathrm{~nm}$ ). The discrepancy that was found between the pore structures of organic matter in these two sets of samples is mostly due to the different thermal maturity level of the samples from the Longmaxi and Bakken Formations. Thermal maturity index of the Longmaxi samples is around 2.5\%-3.5\% (Zhao et al. 2017a, b) which shows the gas generation window, while the maturity index of the Bakken samples is around $0.8 \%$ (Liu et al. 2017) which represents the early to middle oil generation window. When the organic matter starts to undergo thermal maturity to produce hydrocarbons, first, micropores are expected to form within the organic matter and, with increasing maturity, micropores will be converted into meso-macropores (Chen and Xiao 2014).

\section{Conclusions}

In this study, we analyzed and compared pore structures of the samples from two major shale plays in the world. The Bakken Formation (shale oil) and the Longmaxi Formation (shale gas) were studied and compared extensively by gas adsorption methods. Based on this outcome, the following conclusions can be drawn:

1. $\mathrm{N}_{2}$ adsorption isotherms show that the Longmaxi Formation has wider hysteresis loops compared to the Bakken Formation. The hysteresis loop shows that samples from the Longmaxi Formation have more narrow-necked "ink-bottle shaped" pores, while the pores in samples from the Bakken Formation are mainly cylindrical and slit shaped.
2. The Longmaxi Formation has a larger micro/mesomacropore surface area and less average micro/mesomacropore sizes than the Bakken Formation.

3. Based on the main peaks of the micropore size distribution from the $\mathrm{CO}_{2}$ adsorption, most of the micropores in the Longmaxi Formation are less than $1 \mathrm{~nm}$ in size, while in the Bakken Formation, most micropores are larger than $1 \mathrm{~nm}$. The deconvolution results from the pore size distributions of $\mathrm{N}_{2}$ adsorption data show that samples from the Longmaxi Formation have 3 pore size clusters, while samples from the Bakken Formation can be separated into 5 different pore size families with three families similar to the pore clusters in the Longmaxi Formation.

4. The Bakken Formation has less significant micropore heterogeneity and more meso-macropore heterogeneity than the Longmaxi Formation.

5. Organic matter and pyrite are the two main compositions that affect the pore structures. Organic pores with various pore sizes (micropores to macropores) exist in the Longmaxi shale, while the main organic pores in the Bakken shale are micropores.

6. The PLS analysis results show that the influence of some minerals (quartz, feldspar and clay minerals) on the pore structures of the Longmaxi shale is different from their effect on the Bakken shale.

Acknowledgements The authors appreciate Miss Fowler Hallie and Miss Huijing Nie from Core Laboratory for the sample preparation. The authors also appreciate the joint support from China Scholarship Council (201406450029), National Natural Science Foundation of China (Grant No. 41504108), China Postdoctoral Science Foundation (Grant No. 2015M582568).

Open Access This article is distributed under the terms of the Creative Commons Attribution 4.0 International License (http://creative commons.org/licenses/by/4.0/), which permits unrestricted use, distribution, and reproduction in any medium, provided you give appropriate credit to the original author(s) and the source, provide a link to the Creative Commons license, and indicate if changes were made.

\section{References}

Amankwah KAG, Schwarz JA. A modified approach for estimating pseudo-vapor pressures in the application of the DubininAstakhov equation. Carbon. 1995;33:1313-9. https://doi.org/10. 1016/0008-6223(95)00079-S.

Bernard S, Horsfield B, Schulz HM. Geochemical evolution of organic-rich shales with increasing maturity: a STXM and TEM study of the Posidonia Shale (Lower Toarcian, Northern Germany). Mar Pet Geol. 2012;31(1):70-89. https://doi.org/10. 1016/j.marpetgeo.2011.05.010.

Bowker KA. Barnett shale gas production, Fort Worth Basin: issues and discussion. AAPG Bull. 2007;91(4):523-33. https://doi.org/ 10.1306/06190606018. 
Cai J, Yu B. A discussion of the effect of tortuosity on the capillary imbibition in porous media. Transp Porous Media. 2011;89(2):251-63. https://doi.org/10.1007/s11242-011-9767-0.

Chen J, Xiao X. Evolution of nanoporosity in organic-rich shales during thermal maturation. Fuel. 2014;129:173-81. https://doi. org/10.1016/j.fuel.2014.03.058.

Chhabra A, Jensen RV. Direct determination of the $f(\alpha)$ singularity spectrum. Phys Rev Lett. 1989;62:1327. https://doi.org/10.1103/ PhysRevLett.62.1327.

Clarkson CR, Solano N, Bustin RM, Bustin ARM, Chalmers GRL, He $\mathrm{L}$, et al. Pore structure characterization of North American shale gas reservoirs using USANS/SANS, gas adsorption, and mercury intrusion. Fuel. 2013;103:606-16. https://doi.org/10.1016/j.fuel. 2012.06.119.

Costa EVL, Nogueira RA. Fractal, multifractal and lacunarity analysis applied in retinal regions of diabetic patients with and without nonproliferative diabetic retinopathy. Fractal Geom Nonlinear Anal Med Biol. 2015;1(3):112-9. https://doi.org/10. 15761/FGNAMB.1000118.

Do DD, Do HD. Pore characterization of carbonaceous materials by DFT and GCMC simulations: a review. Adsorpt Sci Technol. 2003;21(5):389-423. 026361703769645753.

Fan L, Ziegler T. Nonlocal density functional theory as a practical tool in calculations on transition states and activation energies. Applications to elementary reaction steps in organic chemistry. J Am Chem Soc. 1992;114:10890-7. https://doi.org/10.1021/ ja00053a027.

Feder J. Fractals. New York: Plenum Press; 1988.

Ferreiro JP, Wilson M, Vázquez EV. Multifractal description of nitrogen adsorption isotherms. Vadose Zone J. 2009;8:209-19. https://doi.org/10.2136/vzj2008.0007.

Ferreiro JP, Miranda JGV, Vázquez EV. Multifractal analysis of soil porosity based on mercury injection and nitrogen adsorption. Vadose Zone J. 2010;9:325-35. https://doi.org/10.2136/vzj2009. 0090.

Gao ZY, Hu QH. Estimating permeability using median pore-throat radius obtained from mercury intrusion porosimetry. J Geophys Eng. 2013;10(2):025014. https://doi.org/10.1088/1742-2132/10/ 2/025014.

Gould DJ, Vadakkan TJ. Multifractal and lacunarity analysis of microvascular morphology and remodeling. Microcirculation. 2011;18(2):136-51. https://doi.org/10.1111/j.1549-8719.2010. 00075.x.

Groen JC, Peffer LAA, Pérez-Ramírez J. Pore size determination in modified micro-and mesoporous materials. Pitfalls and limitations in gas adsorption data analysis. Micropor Mesopor Mat;. 2003;60(1):1-17. https://doi.org/10.1016/S1387-1811(03)003391.

Guo T. Discovery and characteristics of the Fuling shale gas field and its enlightenment and thinking. Earth Sci Front. 2016;2016(23):29-43 (in Chinese with English abstract).

Halsey TC, Hensen MH, Kadanoff LP, et al. Fractal measures and their singularities: the characterization of strange sets. Phys Rev A. 1986;33(2):1141-51. https://doi.org/10.1103/PhysRevA.33. 1141.

Hu QH, Liu H, Yang R, et al. Applying molecular and nanoparticle tracers to study wettability and connectivity of Longmaxi Formation in Southern China. J Nanosci Nanotechnol. 2017;17(9):6284-95. https://doi.org/10.1166/jnn.2017.14428.

Huang XF, Zhao YP. Characterization of pore structure, gas adsorption, and spontaneous imbibition in shale gas reservoirs. J Pet Sci Eng. 2017;59:197-204. https://doi.org/10.1016/j.petrol. 2017.09.010
Javadpour F. Nanopores and apparent permeability of gas flow in mudrocks (shales and siltstone). J Can Pet Technol. 2009;48(8):18-21. https://doi.org/10.2118/09-08-16-DA.

Jin H, Sonnonberg SA, Sarg JF. Source rock potential and sequence stratigraphy of Bakken Shales in the Williston Basin. URTEC 2169797 presented at unconventional resources technology conference in San Antonio, Texas. 20-22 July; 2015. https:// doi.org/10.2118/178657-MS.

Klaver J, Desbois G, Urai JL, Littke R. BIB-SEM study of the pore space morphology in early mature Posidonia Shale from the Hils area, Germany. Int J Coal Geol. 2012;103(1):12-25. https://doi. org/10.1016/j.coal.2012.06.012.

Landers J, Gor GY, Neimark AV. Density functional theory methods for characterization of porous materials. Coll Surf A. 2013;437:3-32. https://doi.org/10.1016/j.colsurfa.2013.01.007.

Li L, Chang L, Le S, Huang D. Multifractal analysis and lacunarity analysis: a promising method for the automated assessment of muskmelon (Cucumis melo L.) epidermis netting. Comput Electron Agric. 2012;88:72-84. https://doi.org/10.1016/j.com pag.2012.06.006.

Li W, Liu HF, Song XX. Multifractal analysis of $\mathrm{Hg}$ pore size distributions of tectonically deformed coals. Int J Coal Geol. 2015;144:138-52. https://doi.org/10.1016/j.coal.2015.04.011.

Li JQ, Yu T, Liang X, Zhang PF, Chen C, Zhang J. Insights on the gas permeability change in porous shale. Adv Geo-Energy Res. 2017a;1:63-7.

Li T, Jiang Z, Xu C, et al. Effect of pore structure on shale oil accumulation in the lower third member of the Shahejie formation, Zhanhua Sag, eastern China: evidence from gas adsorption and nuclear magnetic resonance. Mar Pet Geol. 2017b;88:932-49. https://doi.org/10.1016/j.marpetgeo.2017.09. 030 .

Li ZT, Liu DM, Cai YD, et al. Multi-scale quantitative characterization of 3-D pore-fracture networks in bituminous and anthracite coals using FIB-SEM tomography and X-ray $\mu$-CT. Fuel. 2017c;209:43-53. https://doi.org/10.1016/j.fuel.2017.07. 088.

Liu K, Ostadhassan M. Quantification of the microstructures of Bakken shale reservoirs using multi-fractal and lacunarity analysis. J Nat Gas Sci Eng. 2017;39:62-71. https://doi.org/10. 1016/j.jngse.2017.01.035.

Liu K, Ostadhassan M, Zhou J, et al. Nanoscale pore structure characterization of the Bakken shale in the USA. Fuel. 2017;209:567-78. https://doi.org/10.1016/j.fuel.2017.08.034.

Liu K, Ostadhassan M, Zou J, et al. Nanopore structures of isolated kerogen and bulk shale in Bakken Formation. Fuel. 2018a;226:441-53. https://doi.org/10.1016/j.fuel.2018.04.034.

Liu K, Ostadhassan M, Zou J, et al. Multifractal analysis of gas adsorption isotherms for pore structure characterization of the Bakken Shale. Fuel. 2018b;219:296-311. https://doi.org/10. 1016/j.fuel.2018.01.126.

Liu K, Ostadhassan M, Bubach B. Pore structure analysis by using atomic force microscopy. URTEC 2448210. 2016.

Loucks RG, Reed RM, Ruppel SC, et al. Morphology, genesis, and distribution of nanometer-scale pores in siliceous mudstones of the Mississippian Barnett Shale. J Sediment Res. 2009;79(12):848-61. https://doi.org/10.2110/jsr.2009.092.

Mandelbrot BB. Fractals: form, chance, and dimension. New York: W. H. Freeman and Co. 1977.

Mendhe VA, Mishra S, Varma AK, et al. Gas reservoir characteristics of the lower gondwana shales in Raniganj basin of eastern India. J Pet Sci Eng. 2017;149:649-64. https://doi.org/10.1016/j.petrol. 2016.11.008.

Mirzaei-Paiaman A, Saboorian-Jooybari H. A method based on spontaneous imbibition for characterization of pore structure: application in pre-SCAL sample selection and rock typing. J Nat 
Gas Sci Eng. 2016;35:814-25. https://doi.org/10.1016/j.jngse. 2016.09.023.

Mirzaei-Paiaman A, Saboorian-Jooybari H, Pourafshary P. Improved method to identify hydraulic flow units for reservoir characterization. Energy Technol-GER. 2015;3(7):726-33. https://doi. org/10.1002/ente.201500010

Mirzaei-Paiaman A, Ostadhassan M, Rezaee R, Saboorian-Jooybari $\mathrm{H}$, Chen Z. A new approach in petrophysical rock typing. J Pet Sci Eng. 2018;166:445-64. https://doi.org/10.1016/j.petrol.2018. 03.075 .

Monson PA. Understanding adsorption/desorption hysteresis for fluids in mesoporous materials using simple molecular models and classical density functional theory. Micropor Mesopor Mat. 2012;160:47-66. https://doi.org/10.1016/j.micromeso.2012.04. 043.

Pitman JK, Price LC, LeFever JA. Diagenesis and fracture development in the Bakken Formation, Williston Basin: Implications for reservoir quality in the middle member. U.S.G.S. Professional paper 1653. 2001

Riedi RH, Crouse MS, Ribeiro VJ, Baraniuk RG. A multifractal wavelet model with application to network traffic. IEEE Trans Inf Theory. 1999;45:992-1018. https://doi.org/10.1109/18. 761337.

Rouquerolb J, Avnir D, Fairbridge CW, et al. Recommendations for the characterization of porous solids (Technical Report). Pure Appl Chem. 1994;66(8):1739-58. https://doi.org/10.1351/ pac199466081739.

Schmitt M, Fernandes CP, da Cunha Neto JAB, et al. Characterization of pore systems in seal rocks using nitrogen gas adsorption combined with mercury injection capillary pressure techniques. Mar Pet Geol. 2013;39(1):138-49. https://doi.org/10.1016/j. marpetgeo.2012.09.001

Shao X, Pang X, Li Q, et al. Pore structure and fractal characteristics of organic-rich shales: a case study of the lower Silurian Longmaxi shales in the Sichuan Basin, SW China. Mar Pet Geol. 2017;80:192-202. https://doi.org/10.1016/j.marpetgeo.2016.11. 025 .

Sing KS, Everett DH, Haul RAW, Moscou L, Pierotti RA, Rouquerol $\mathrm{J}$, et al Reporting physisorption data for gas/solid systems with special reference to the determination of surface area and porosity. Pure Appl Chem. 1985;57(4):603e619.

Smith M, Bustin M. Sedimentology of the Late Devonian Early Mississippian Bakken Formation, Williston Basin. Presented at the Seventh International Williston Basin Symposium. 23 July; 1995.

Song Y, Jiang B, Shao P, Wu J. Matrix compression and multifractal characterization for tectonically deformed coals by $\mathrm{Hg}$ porosimetry. Fuel. 2018;211:661-75. https://doi.org/10.1016/j. fuel.2017.09.070.

Sonnonberg SA, Jin H, Sarg JF. Bakken Mudrocks of the Williston Basin, World Class Source Rocks. AAPG paper 80171 presented at AAPG annual convention and exhibition at Houston, Texas. 10-13 April; 2011.

Sorelli L, Constantinides G, Ulm F-J, Toutlemonde F. The nanomechanical signature of ultra high performance concrete by statistical nanoindentation techniques. Cem Concr Res. 2008;38(12):1447-56. https://doi.org/10.1016/j.cemconres.2008. 09.002 .

Su Y, Zha M, Ding XJ, et al. Pore type and pore size distribution of tight reservoirs in the Permian Lucaogou Formation of the Jimsar Sag, Junggar Basin, NW China. Mar Pet Geol. 2018;89:761-74. https://doi.org/10.1016/j.marpetgeo.2017.11. 014 .
Tang H, Zhu J, Xi Z, Di X, Wang J, Ao Q. Impact factors of fractal analysis of porous structure. Sci China Technol Sci. 2010;53(2):348-51. https://doi.org/10.1007/s11431-009-0361-4.

Thommes M, Cychosz KA. Physical adsorption characterization of nanoporous materials: progress and challenges. Adsorption. 2014;20(2-3):233-50. https://doi.org/10.1007/s10450-0149606-z.

Thommes M, Kaneko K, Neimark AV, et al. Physisorption of gases, with special reference to the evaluation of surface area and pore size distribution (IUPAC Technical Report). Pure Appl Chem. 2015;87(9-10):1051-69. https://doi.org/10.1515/pac-2014-1117.

Ulm FJ, Vandamme M, Bobko C, et al. Statistical indentation techniques for hydrated nanocomposites: concrete, bone, and shale. J Am Ceram Soc. 2007;90(9):2677-92. https://doi.org/10. 1111/j.1551-2916.2007.02012.x.

Wang L, Fu Y, Li J, et al. Mineral and pore structure characteristics of gas shale in Longmaxi Formation: a case study of Jiaoshiba gas field in the southern Sichuan Basin, China. Arab J Geosci. 2016;9(19):733. https://doi.org/10.1007/s12517-016-2763-5.

Wei W, Cai J, Hu X, Fan P, Han Q, et al. A numerical study on fractal dimensions of current streamlines in two-dimensional and threedimensional pore fractal models of porous media. Fractals. 2015;23(01):1540012. https://doi.org/10.1142/ S0218348X15400125.

Wei Z, Wang Y, Wang G, et al. Pore characterization of organic-rich Late Permian Da-long Formation shale in the Sichuan Basin, southwestern China. Fuel. 2018;211:507-16. https://doi.org/10. 1016/j.fuel.2017.09.068.

Wold S, Sjöström M, Eriksson L. PLS-regression: a basic tool of chemometrics. Chemom Intell Lab. 2001;58(2):109-30. https:// doi.org/10.1016/S0169-7439(01)00155-1.

Xia Y, Cai J, Wei W, Hu X, Wang X, Ge X. A new method for calculating fractal dimensions of porous media based on pore size distribution. Fractals. 2018;26(1):1850006. https://doi.org/ $10.1142 / \mathrm{S} 0218348 \mathrm{X} 18500068$.

Yang $\mathrm{R}, \mathrm{He} \mathrm{S}, \mathrm{Hu} \mathrm{QH}$, et al. Applying SANS technique to characterize nano-scale pore structure of Longmaxi shale, Sichuan Basin (China). Fuel. 2017;197:91-9. https://doi.org/10. 1016/j.fuel.2017.02.005.

Yin M, Huang H, Ma J. Pore size constrains on hydrocarbon biodegradation in shales from the Second White Speckled Shale Formation of the Western Canada Sedimentary Basin. Fuel. 2016;185:639-48. https://doi.org/10.1016/j.fuel.2016.08.034.

Zhang Y, Xu X, Lebedev M, et al. Multi-scale X-ray computed tomography analysis of coal microstructure and permeability changes as a function of effective stress. Int $\mathrm{J}$ Coal Geol. 2016;165:149-56. https://doi.org/10.1016/j.coal.2016.08.016.

Zhao J, Jin Z, Hu QH, et al. Integrating SANS and fluid-invasion methods to characterize pore structure of typical American shale oil reservoirs. Sci Rep. 2017a;7:15413. https://doi.org/10.1038/ s41598-017-15362-0.

Zhao PQ, Wang Z, Sun Z, et al. Investigation on the pore structure and multifractal characteristics of tight oil reservoirs using NMR measurements: Permian Lucaogou Formation in Jimusaer Sag, Junggar Basin. Mar Pet Geol. 2017b;86:1067-81. https://doi.org/ 10.1016/j.marpetgeo.2017.07.011.

Zhao X, Qiu Z, Sun B, Liu S, et al. Formation damage mechanisms associated with drilling and completion fluids for deepwater reservoirs. J Pet Sci Eng. 2019;173:112-21. https://doi.org/10. 1016/j.petrol.2018.09.098.

Zou J, Rezaee R, Liu K. The effect of temperature on methane adsorption in shale gas reservoirs. Energy Fuels. 2017;31:12081-92. https://doi.org/10.1021/acs.energyfuels. $7 b 02639$. 